\title{
Setting objectives: the key to successful mine closure
}

\author{
M Fawcett Coffey International Ltd, Australia
}

T Laurencont Coffey International Ltd, Australia

\begin{abstract}
The desired outcome of remediation is to eliminate or minimise to an acceptable level the social and environmental impacts of a mining operation post-closure. Remediation objectives should be seen as the overall guiding principles that every activity must be checked against. If remediation objectives are not clearly defined and understood by all parties, none of the subsequent stages of the remediation process can be developed or implemented with accuracy or certainty of success. Ultimately the failure of remediation programs can often be traced back to the failure to undertake a rigorous program to develop and define clear and appropriate remediation objectives at the outset.
\end{abstract}

In this paper the process of developing remediation objectives is explored, including what should be considered as inputs into their development including:

- Final land use.

- Legislation, regulations and agreements.

- Codes of Practice and Guidelines.

- Corporate policies and standards.

- Stakeholder expectation.

- Characterisation of the biophysical and social environment.

How to develop remediation objectives within the context of site constraints will also be discussed. For example, mine closure is often seen as unrestricted release of a site. However, circumstances and considerations such as the remediation option selected, budgetary constraints or the disturbance of valuable habitats, may require limiting or prohibiting access. These limitations can be temporary, as may be expedient in the case of contamination with short-lived nuclides, or long-term, as for tailings impoundments.

Finally, the process of developing a set of remediation criteria, once the remediation objectives have been decided; to target remediation activities, to assess performance as the work proceeds; and to verify that the remediation objectives have been achieved at its conclusion, will be discussed.

Keywords: objectives, closure, criteria, stakeholders, planning, remediation

\section{Introduction}

Successful implementation of mine remediation and closure programs is dependent on a range of interlinked factors, however the overarching factor is the closure objective. It's this objective that should drive all decisions regarding remediation and mine closure.

In developing the closure objective, it is important to ensure that the process of developing it is not undertaken in isolation by the site owner or operator. For the closure objective to be appropriate it must result from a process of consultation with stakeholders and must have their agreement. Lack of agreement about the objective can, and has, led to failure of a program, which in turn leads to stakeholder conflict, delayed relinquishment and significantly increased risk and costs. 
It is the authors' experience that the failure of remediation programs and mine closures can often be traced back to one or more of the following:

- Lack of objectives.

- Poorly developed objectives.

- Lack of stakeholder agreed objectives.

Objectives should ideally be set at the design stage of a project, at least to a conceptual stage, they will then provide the guidance for each part of the operations life. Setting them at the start will give the best chance of ultimately relinquishing the site. Failure to set them until the operation has ceased production may mean that decisions have been made, or the site operated in such a manner that relinquishment can never be achieved, and the operator is tied to perpetual management and maintenance of the site. There is also the impact on community perceptions of the industry and maintenance of the operators, and more broadly, the industry's social licence to operate. Figure 1 illustrates the importance of setting objectives as early as possible in the life of an operation as this provides the opportunity to consider the greatest range of options that can meet the objectives at the lowest possible cost.

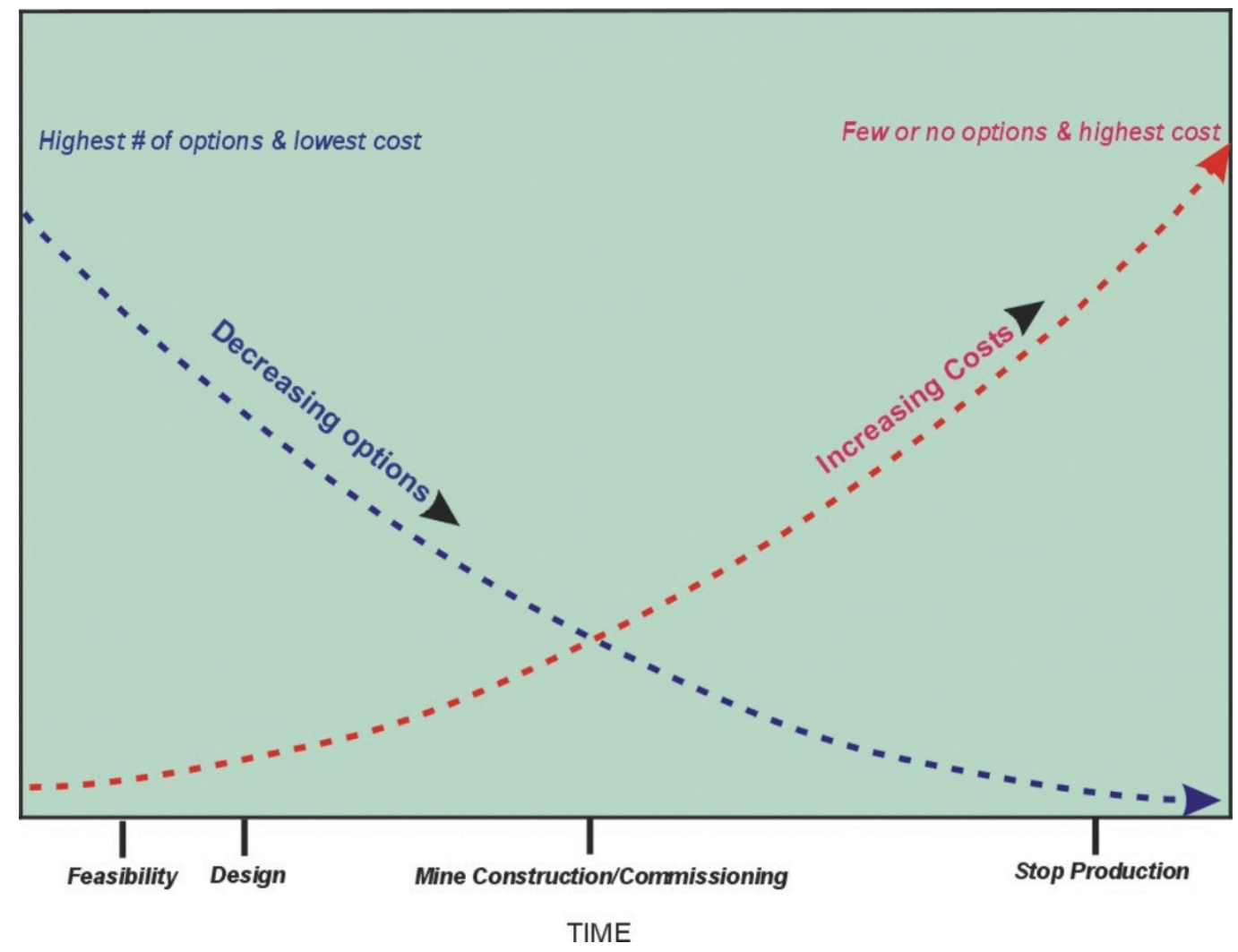

Figure 1 Importance of developing objectives early on showing the relationship between increasing cost and reduced closure options as a project progresses (Fawcett 2002)

All decisions and activities must be checked for conformance with remediation objectives.

Remediation objectives will reflect the overall values that the operator, stakeholders, regulators and general community place on the physical and social environment in which the operation is located. Typically, they will have a location or regional specific basis. These overall values will generally address the following components of closure:

- Sustainability.

- Land use.

- Safety and human health. 
- Social impacts.

- Ecosystem impacts.

- Regulatory requirements.

- Corporate policies and codes of practice.

There will generally be a number of sub-objectives that fall underneath the sites overarching objective. An example of an overall objective is:

XXX NL intends to the undertake works that will, to the greatest extent practicable allow the site over time to return to its pre-mining condition and to rehabilitate the site such that any residual impacts from the mining and processing operation; do not impact on the subsequent land use opportunities of the landholders, or where a limiting impact has been identified it can be demonstrated that it will diminish over an acceptable period of time.

From this, sub-objectives will be developed for specific aspects or domains of the site, these will include areas such as:

- Groundwater.

- Surface water.

- Containment structures (tailings storage facilities, waste rock dumps, dams etc.)

- Vegetation reestablishment.

- Land use.

It is the authors' experience that sites often confuse objectives and criteria which leads to arbitrary targets being set without sound substantiation.

- Remediation objectives - what we want to achieve (where we want to end up).

- Remediation criteria - how we will achieve the objectives (measurable).

\section{$2 \quad$ Developing closure objectives}

The main inputs into developing objectives are:

- Final (post-remediation) land use for the site. There may be multiple uses across the site depending on its location, size and history of mining and processing activities.

- Legislation and regulations.

- Codes of practice and guidelines (e.g.: ICMM guidelines, various state Mine Closure Guidelines).

- Corporate policies - many companies have now developed internal closure standards.

- Stakeholder expectations and commitments.

- Characterisation.

Figure 2 sets out the inputs to determining appropriate objectives and the order of activities that follow on. 


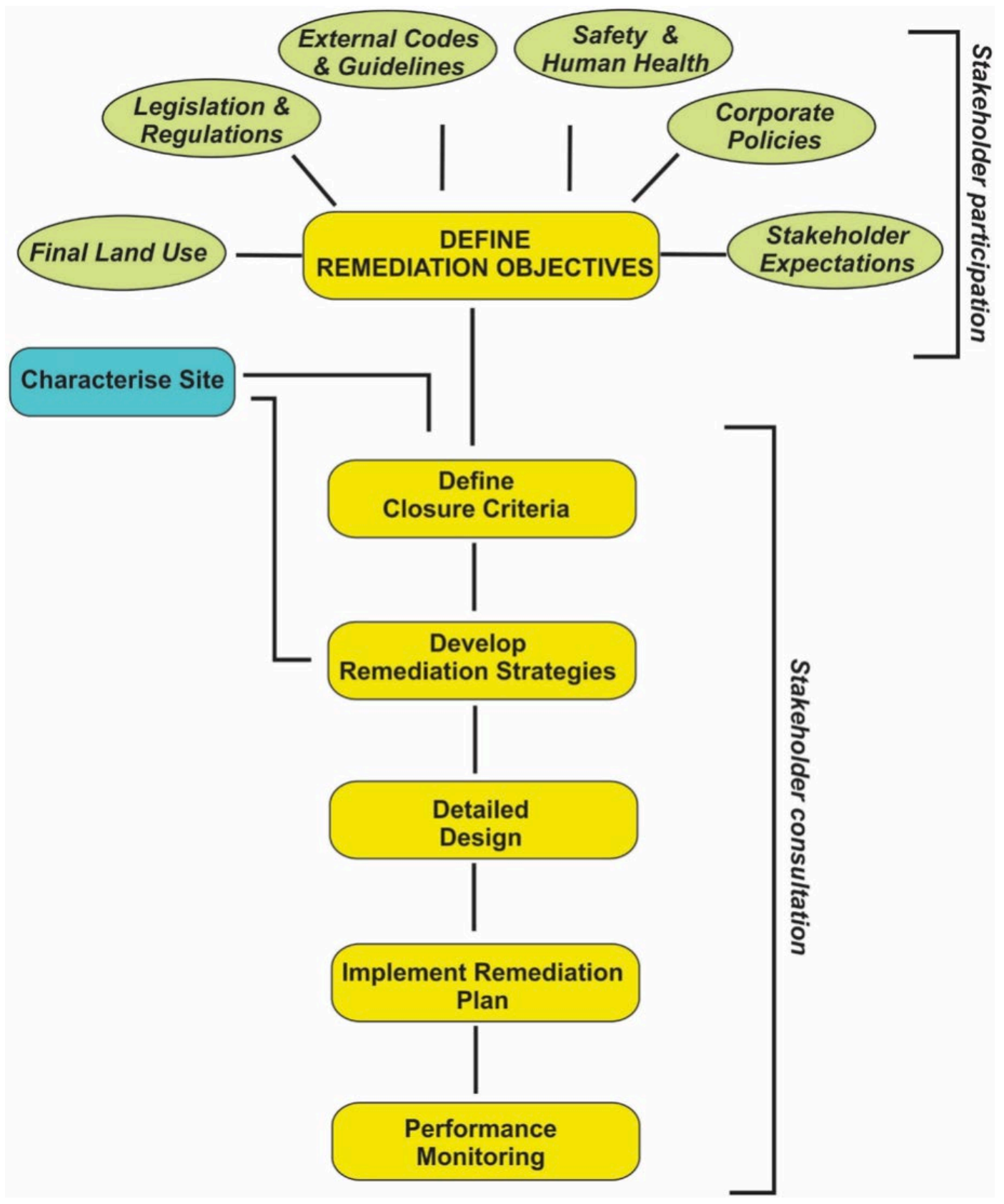

Figure 2 Flow chart for objectives, criteria and remediation options and the inputs to developing objectives and stakeholder engagement

\subsection{Sustainability}

Remediation activities ought not, to the maximum extent practicable, impact on, or limit the potential for future development of the site, by causing either; the permanent alienation of land from future beneficial land-uses, or sterilisation of currently sub-economic resources.

\section{$2.2 \quad$ Land use}

Remediation strategies ought not to cause an ongoing liability or risk to accrue to landowners and/or stakeholders.

Careful planning is needed to ensure that remediation strategies, to the maximum extent practicable, are maintenance free and minimise requirements for ongoing management or intervention, and where appropriate incorporate traditional human activities. 


\subsection{Safety and human health}

Human safety considerations are of paramount importance.

Remediation activities need to take account of human health considerations in all aspects of planning and execution and where potential for adverse impacts on human health is identified, plans are developed to prevent such impacts occurring.

\subsection{Social impacts}

Stakeholders are identified, their concerns and aspirations are heard, and they are fully integrated into the remediation planning process.

\subsection{Ecosystem impacts}

Where an ecosystem impact has been identified it can either be demonstrated that it will diminish over an acceptable timescale, or the extent of the impact is minimised, by ensuring that best practice technologies are employed, and appropriate resources are provided for the ongoing management of identified impacts.

\subsection{Regulatory requirements}

Remediation objectives must as a minimum be compliant with current legislation and should anticipate changes in legislation and community expectations over the life of the project.

\subsection{Corporate policies and codes of practice}

Remediation objectives must as a minimum be compliant with all codes of practice that the operator is signatory to and comply with any internal corporate policies and procedures.

\section{Developing closure criteria}

Once the remediation objectives have been decided, a set of remediation criteria must be developed to guide remediation activities, assess performance as the work proceeds, and to verify that the remediation objectives have been achieved at its conclusion. Or if they are not being met, then to determine the reason why and guide corrective actions. This section provides examples of the process of developing closure criteria that address the closure objectives.

The criteria may include but should not be limited to:

- Radiological/radiation protection criteria (maximum dose rate, residual concentration levels).

- Emission criteria (concentration limits, action levels).

- Geomechanical criteria (slope stability, seismic stability).

- Geotechnical criteria (thickness of cover layers, properties of cover layers, soil compaction specifications).

- Geochemical criteria (precipitation/solution reactions).

- Hydrochemical criteria (concentration levels in seepage, groundwater).

- Hydraulic criteria (flow rates, hydraulic capacity of pipes, drain etc.).

- Technical performance criteria (infiltration/exhalation rates, erosion rates).

- Social criteria (local employment, local purchasing).

- Cost criteria (unit costs, overall investment/construction costs).

- Scheduling criteria (project start/end, critical path). 


\section{$4 \quad$ Implementing closure objectives}

Having clearly defined and agreed closure objectives provides a high level of confidence for the implementation phase and allows different implementation strategies to be evaluated against a common outcome. This can be particularly important with respect to cash flow and social impact. It also sets clear boundaries that various options must remain within, as illustrated in Figure 3.

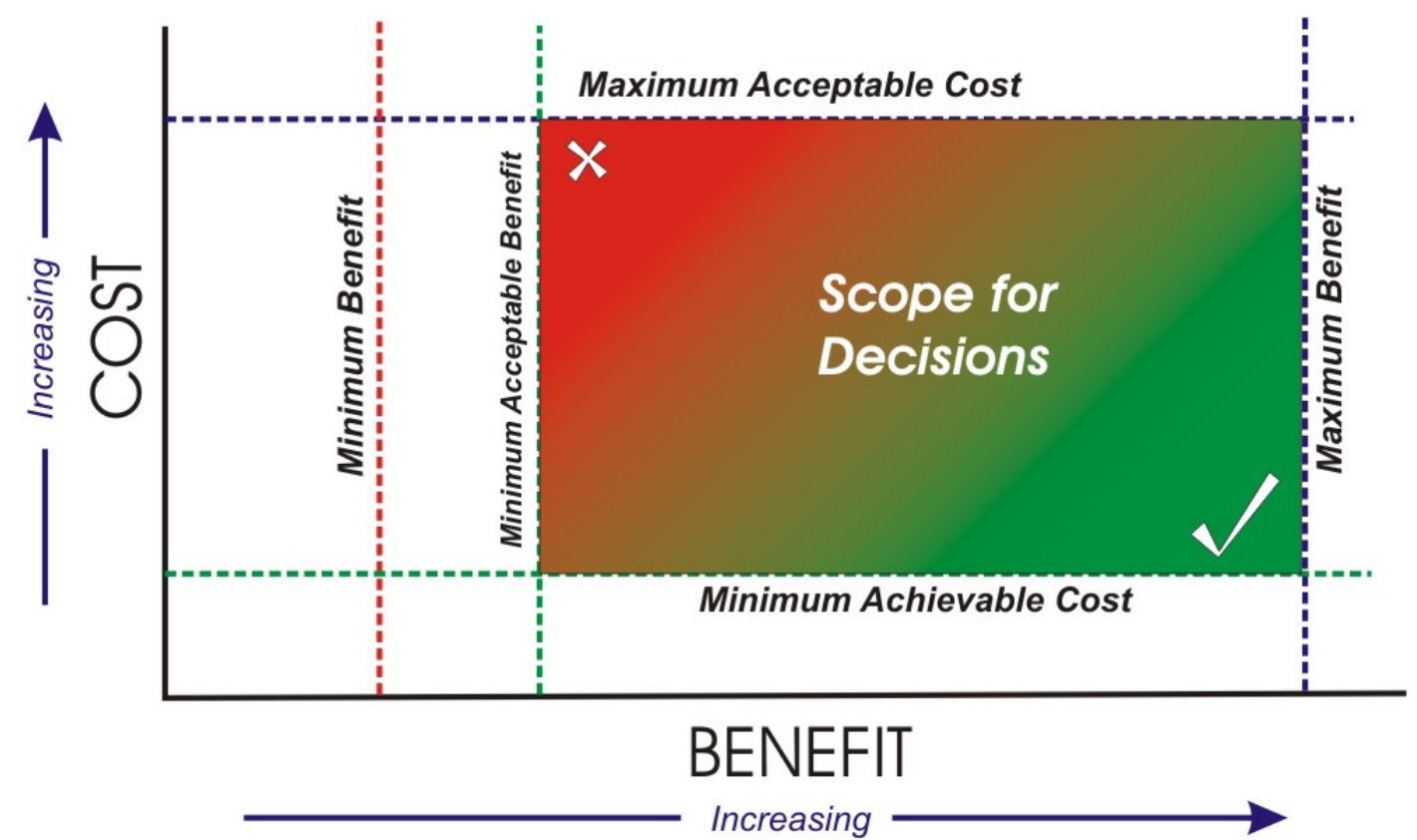

Figure 3 Scope for decision-making whilst meeting objectives within minimum acceptable benefit and cost parameters

Once closure objectives have been developed and agreed to it is necessary to determine the most appropriate method to achieving them. The methodology selected to achieving them will be site specific, after accounting for regional and social considerations. Implementation methodologies may be significantly different in Australia compared with those in less developed locations. This is where the social impacts objectives may become dominant. Figure 4 shows how the balance of emphasis between the social, financial and technical may vary from site to site depending on each site's unique requirements.

Figure 4 illustrates how there may be multiple remediation scenarios for a site component that will still meet the overall objective, however when the sub-objectives are also considered a preference for one may become obvious once specific site or social conditions are assessed.

For a specific objective there may be more than one feasible technical solution available, for this example a mine waste containment structure is used. The factors influencing the decision-making process at this point are:

- Investment costs for constructing containment or disposal facilities.

- Long-term cost for operating, maintaining and monitoring.

- Long-term stability of engineered facilities.

- Regulatory acceptance.

- Stakeholder acceptance. 

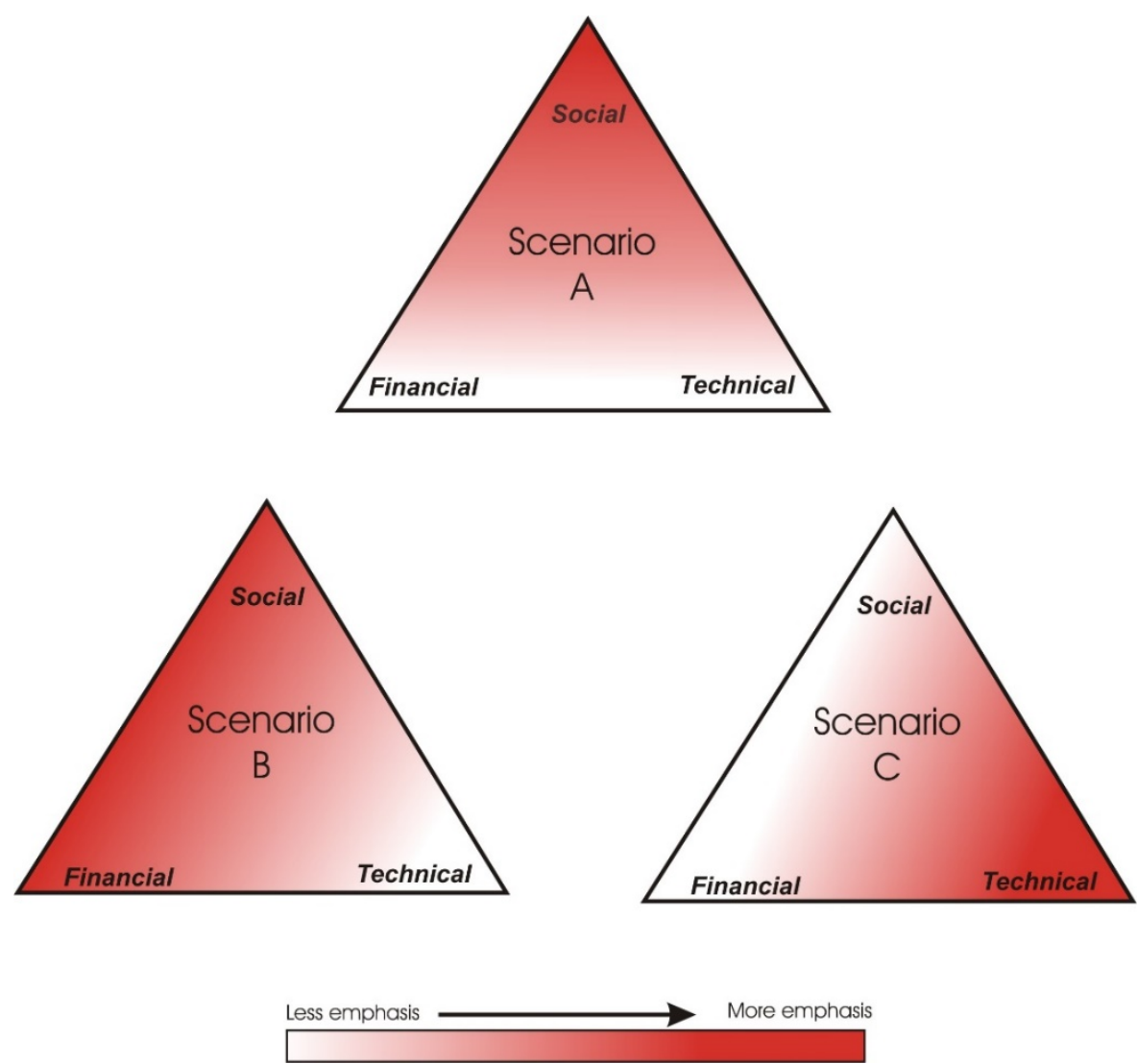

Figure 4 Emphasis of inputs when assessing strategies will be project specific and reflect local socioeconomic conditions, technical challenges and financial resources available.

Figure 5 illustrates the situation where total cost for meeting the objective is similar, however resources (local employment) availability is limited, there is the option to achieve the same outcome at a similar cost with a smoother cash flow.

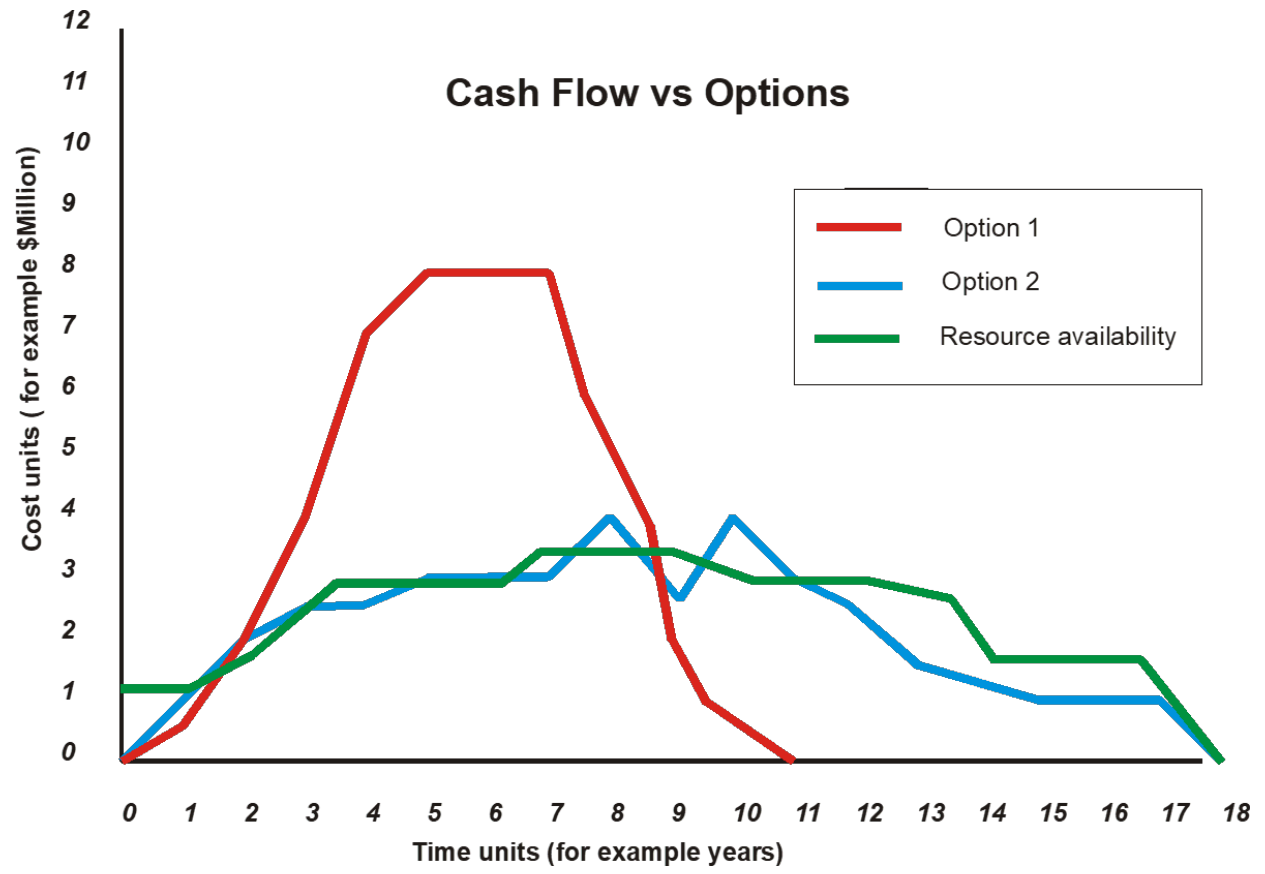

Figure 5 Cash flow versus options and resource availability illustrating that selection of remediation options may need to consider cash flow and other resource availability 
This example will likely better align with the social objective whilst still meeting the technical objective.

\section{Conclusion}

Defining agreed closure objectives early on in an operation's life, preferably at the design stage, will minimise costs over the life of the operation, provide guidance for all activities and optimise the likelihood of early relinquishment of the site. They will also optimise relationships with stakeholders by providing them with confidence in how the site will be operated and closed and provide operators with clear understanding of their expectations.

The life of a site and the obligations of the owner/operator commence before operations begin and extend well beyond the completion of operations. Without setting objectives early on, the owner/operator may lock themselves/itself into perpetual maintenance of the site to manage its impacts at worst, or at best, only have high-cost remediation options available.

\section{References}

Fawcett, M 2002, Provisioning for Mine Closure, ACMER Short Course on Achieving Sustainable Mine Closure Outcomes, Darwin, 27 September. 